\title{
Circular heat and solute source within a viscoplastic porous enclosure: The critical source dimension for optimum transfers
}

\author{
Karim Ragui $^{*}$, Abdelkader Boutra ${ }^{1,2}$, Youb Khaled Benkahla ${ }^{1}$, Rachid Bennacer ${ }^{3}$ \\ ${ }^{1}$ Laboratory of Transfer Phenomenon, University of Sciences and Technology Houari Boumediene. Algiers, Algeria \\ ${ }^{2}$ Superior School of Applied Sciences. Algiers, Algeria \\ ${ }^{3}$ LMT - ENS Cachan, CNRS, Paris - Saclay University, 94230 Cachan, France
}

Corresponding Author Email: ragui-karim@live.fr

https://doi.org/10.18280/ijht.360243

Received: 13 November 2017

Accepted: 28 April 2018

\section{Keywords:}

thermosolutal convection, bingham plastics, porous medium, circular pollutant source, finite volume approach, cut-cell approach, proposed models

\begin{abstract}
Through our paper, thermosolutal convection of viscoplastic materials 'so called Bingham plastics' which occurs into a porous matrix with an inner pollutant source has been treated numerically, in the aim to light out the impact of some relevant parameters; such Lewis and porous Rayleigh numbers; as well as the buoyancy ratio and the source dimension one; on a such conjugate phenomenon. To do so, the physical model for the momentum conservation equations is made using the Brinkman extension of the classical Darcy equation. The set of coupled equations is solved using the finite volume method and the SIMPLER algorithm. The heat and solute source within the porous space has taken a circular shape. Simply said, our pollutant source is a transport pipe which presented in 2D. To handle the latter in Cartesian Coordinates; the Cartesian Cut-Cell approach was adopted. After a careful treatment of such double-diffusive convection within the Bingham-porous space; powerful expressions that expect the mean transfer rates in such industrial geometry are set forth as a function of the governing parameters. These correlations, which predicted with $\pm 3 \%$ the numerical results, may count as a complement to previous Newtonian-fluid researches. It is to note that the validity of the computing code was ascertained by comparing our results with experimental data and numerical ones, already available in the literature.
\end{abstract}

\section{INTRODUCTION}

During the last few decades, the field of heat and mass transfers within a porous medium has been the subject of a very intense research activity, due to its importance of related industries and contemporary technological applications. Prominent among these applications being geothermal energy resources; nuclear energy systems; petroleum reservoirs; analysis of insulating systems; grain storage; pollutant dispersion in aquifers; processes of crystal manufacture, foam metals and fibrous media; to name but a few [1-3].

With both temperature and concentration gradients present to drive the fluid flow, an increased number of transport configurations was achievable with parallel or perpendicular gradients, and the body forces augmenting or opposing [4-10].

In the main idea to predict the transfer coefficients within such configurations, powerful expressions were proposed over the years. Back to 1987, and within a porous square, Trevisan and Bejan [11] projected the transfer rates of a Newtonian fluid as a function of boundary layers' ratio, known generally as Lewis number, porous buoyancy, known as the Rayleigh-Darcy combination $\left(\mathrm{Ra}^{*}=\mathrm{Ra}_{\mathrm{T}} \mathrm{Da}\right)$; as well as a geometry' aspect ratio and a thermosolutal buoyancy one; which is a pure relation between the thermosolutal gradients and its expansion coefficients $\left(\mathrm{N}=\beta_{\mathrm{C}} \Delta \mathrm{C} / \beta_{\mathrm{T}} \Delta \mathrm{T}\right)$. A few years later, Lin et al. [12] accomplished the Trevisan \& Bejan predictions by Nusselt and Sherwood correlations; respect to the thermal Grashof numbers for small thermosolutal buoyancy ratios $(|\mathrm{N}|<5)$.
Reaching 1993, Bennacer [13] treated the square matrix cases by using a critical ratio between the thermosolutal buoyancies and the boundary layers' values (i.e. N/Le). By the means of such key ratio; Bennacer suggested new and global expressions for the transfer coefficients within such geometries. These correlations were judged available through a wide range of the pertinent parameters; what made a strong base for future developed investigations.

Recently, Ragui et al. [14] accomplished such correlations by treating the case of a bottom polluting source within a porous enclosure. Such numerical work made the pollutants spreading and the fuel leaks much predictable by using developed expressions of thermosolutal coefficients which meant for such problems. These expressions were judged available for a wide range of the previous pertinent parameters, side by side with the polluting source length.

On the subject of the industrial flows' problems, within various geometries, the Newtonian fluids may present a simple limit of the complex ones, such the Crude Oil and pharmaceutics' products, to name but a few. The illumination of Bingham' researches, done in between 1916 and 1922 [1516], has opened a new research axes for such special fluids; so called, after, as Bingham plastics.

Such Viscoplastic materials can act as a Newtonian fluid under a specific shear stress value, and a gel-like material up to that value; what make the transfer rates predictions of such fluids so complicated, experimentally speaking or numerically [17]. Going far with its complexity, and within a porous matrix, both the porosity and the permeability could 
present the key factor to predict the behavior of yielded and unyielded regions [18-19].

Motivated by such complication; and by the fact that double-diffusive convection of Bingham plastics may less common in the available literature, our paper will discuss predictions of such phenomenon within a complex geometry, as the porous matrix with a centered polluting source of a circular shape (simply said; a 2D pipeline).

Complement to what's presented in our previous works [14-20], the main purpose of this contribution is to light-up the impact of some pertinent parameters, such the boundary layers' ratio and the buoyancy one; side by side with the polluting source dimension, to come out at the end with primary expressions that may predict the mean transfer rates of such complex fluids within the solid matrix. Such studied geometry may plot an interesting work for many industrial applications, especially in Refining and Petrochemical fields.

\section{PROBLEM STATEMENT \& MATHEMATICAL FORMULATION}

The studied configuration, shown by Fig. 1, consists of a cold "and a less concentric" side-walls of a square porous space in which; a thermal and solutal circular source is mounted at the middle. The fluid which filled the porous matrix is assumed to be viscoplastic and obeying the Bingham rheological model, (i.e. Bingham case) [21-22]. Its thermophysical properties are presumed to be constants; except the density variation in the buoyancy term; which depends linearly to the local temperature and concentration [23]; as well as the viscosity " $\eta$ " which is a yield stress' function [24]. See equations below for instance:

$\rho_{(\mathrm{T}, \mathrm{C})}=\rho_{0}\left[1-\beta_{\mathrm{T}}\left(\mathrm{T}-\mathrm{T}_{0}\right)-\beta_{\mathrm{C}}\left(\mathrm{C}-\mathrm{C}_{0}\right)\right]$

where $\beta_{\mathrm{T}}$ and $\beta_{\mathrm{C}}$ are the thermal and the concentration expansion coefficients; which can be defined as:

$$
\begin{aligned}
& \beta_{\mathrm{T}}=-\frac{1}{\rho_{0}}\left[\frac{\partial \rho}{\partial \mathrm{T}}\right]_{\mathrm{p}} \quad ; \quad \beta_{\mathrm{C}}=-\frac{1}{\rho_{0}}\left[\frac{\partial \rho}{\partial \mathrm{C}}\right]_{\mathrm{p}} \\
& \eta=\mu_{\mathrm{p}}+\frac{\tau_{0}}{|\dot{\gamma}|}[1-\exp (-\mathrm{m}|\dot{\gamma}|)]
\end{aligned}
$$

where $|\dot{\gamma}|$ is the magnitude of the symmetric rate-of strain tensor $\stackrel{\bar{\gamma}}{\bar{\gamma}}$, which can be defined as:

$$
\left\{\begin{array}{l}
|\dot{\gamma}|=\left(\frac{1}{2} \mathrm{II}_{\dot{\gamma}}\right)^{1 / 2}=\left[\frac{1}{2}\{\overline{\bar{\gamma}}:=\overline{\dot{\gamma}}\}\right]^{1 / 2} \\
\overline{\bar{\gamma}}=\nabla \overline{\mathrm{v}}+\nabla \overline{\mathrm{v}}^{\mathrm{T}}
\end{array}\right.
$$

$\nabla_{\mathrm{v}}^{-}$is the velocity gradient tensor; when $\nabla_{\mathrm{v}}^{-\mathrm{T}}$ is its transpose.

Noted that "m" is the exponential growth parameter of Papanastasiou [24] which is a function of both the yield stress $\tau_{0}$ and the plastic viscosity $\mu_{\mathrm{p}}[17]$.

The solid matrix is assumed to be rigid, isotropic, homogeneous and in thermal equilibrium with the complex fluid $[17,25]$. The mass diffusion within the solid matrix is neglected side by side with Soret and Dufour effects
Regarding the present investigation, the permeability of the porous medium is kept uniform and its equivalent Darcy value is about $10^{-3}$. As well, the porosity is equal to $40 \%$.

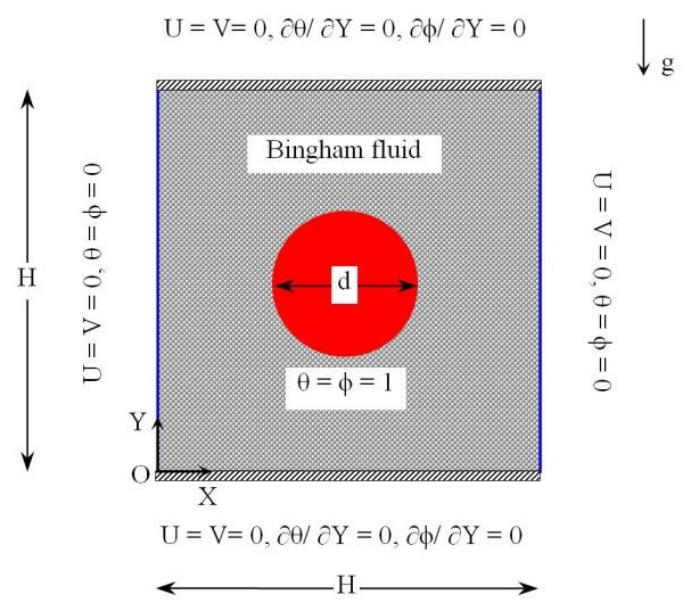

Figure 1. Simulation domain with its boundary conditions

which reflects the case of the industrial Silicon Carbide ceramic (i.e. $\mathrm{SiC}$ ) [26]

Adopting the 2D Brinkman extension of the classical Darcy equation under steady-state conditions; the conservation equations which describe the transport phenomenon of the viscoplastic fluid within the porous square can be summarized as follows [17, 27-30]:

$$
\vec{\nabla} \overrightarrow{\mathrm{V}}=0
$$

$\frac{\rho}{\varepsilon^{2}}(\vec{V} \cdot \vec{\nabla}) \vec{V}=\rho \vec{g}-\vec{\nabla} p-\frac{\eta}{K} \vec{V}+\vec{\nabla} \cdot=$

$\overrightarrow{\mathrm{V}} \cdot \vec{\nabla} \mathrm{T}=\frac{\mathrm{k}}{\rho \mathrm{C}_{\mathrm{p}}} \nabla^{2} \mathrm{~T}$

$\overrightarrow{\mathrm{V}} \cdot \vec{\nabla} \mathrm{C}=\mathscr{D} \nabla^{2} \mathrm{C}$

where $\varepsilon$ displays the porosity, $\mathrm{C}_{\mathrm{p}}$ the specific heat at a constant pressure, $\mathrm{k}$ the thermal conductivity; when $\mathscr{D}$ is for the mass diffusivity. $\eta$ is the complex effective viscosity and $\bar{\tau}$ the viscous stress' tensor.

\section{NUMERICAL PROCEDURE}

Regarding the numerical procedure, the Cartesian Cut-Cell approach, also called Cartesian Grid method [31], is adopted to handle the pollutant source' limits, (see for instance Fig.2). As such, the control volumes found within are assumed to be inactive, following the inequality equation "Eq. 4". Simply said, neither fluid movements nor thermosolutal transfers are denoted within the inner source " $\mathrm{U}=\mathrm{V}=0, \mathrm{~T}=\mathrm{T}_{\mathrm{h}}, \mathrm{C}=\mathrm{C}^{+}$",

$(\mathrm{x}-0.5)^{2}+(\mathrm{y}-0.5)^{2} \leq\left(\frac{\mathrm{d}}{2}\right)^{2}: \mathrm{U}=\mathrm{V}=0, \mathrm{~T}=\mathrm{T}_{\mathrm{h}}, \mathrm{C}=\mathrm{C}^{+}$

Then, the governing conservation equations are discretized in space using the finite volume approach, when the 
convection and the diffusion terms were treated by a PowerLaw scheme. The resulting algebraic equations, side by side with the associated boundary conditions, are solved, consequently, using the line by line approach [32].

As the momentum equation is formulated in term of the primitive variables $(\mathrm{U}, \mathrm{V}$ and $\mathrm{P}$ ), our iterative procedure includes a pressure correction calculation method, namely
SIMPLE modified [32], to solve the pressure-velocity coupling. Compared to other velocity-pressure coupling approaches, such as SIMPLE and SIMPLEC, the adopted approach has proven to be faster (about 30 to $50 \%$ fewer iterations) [32].

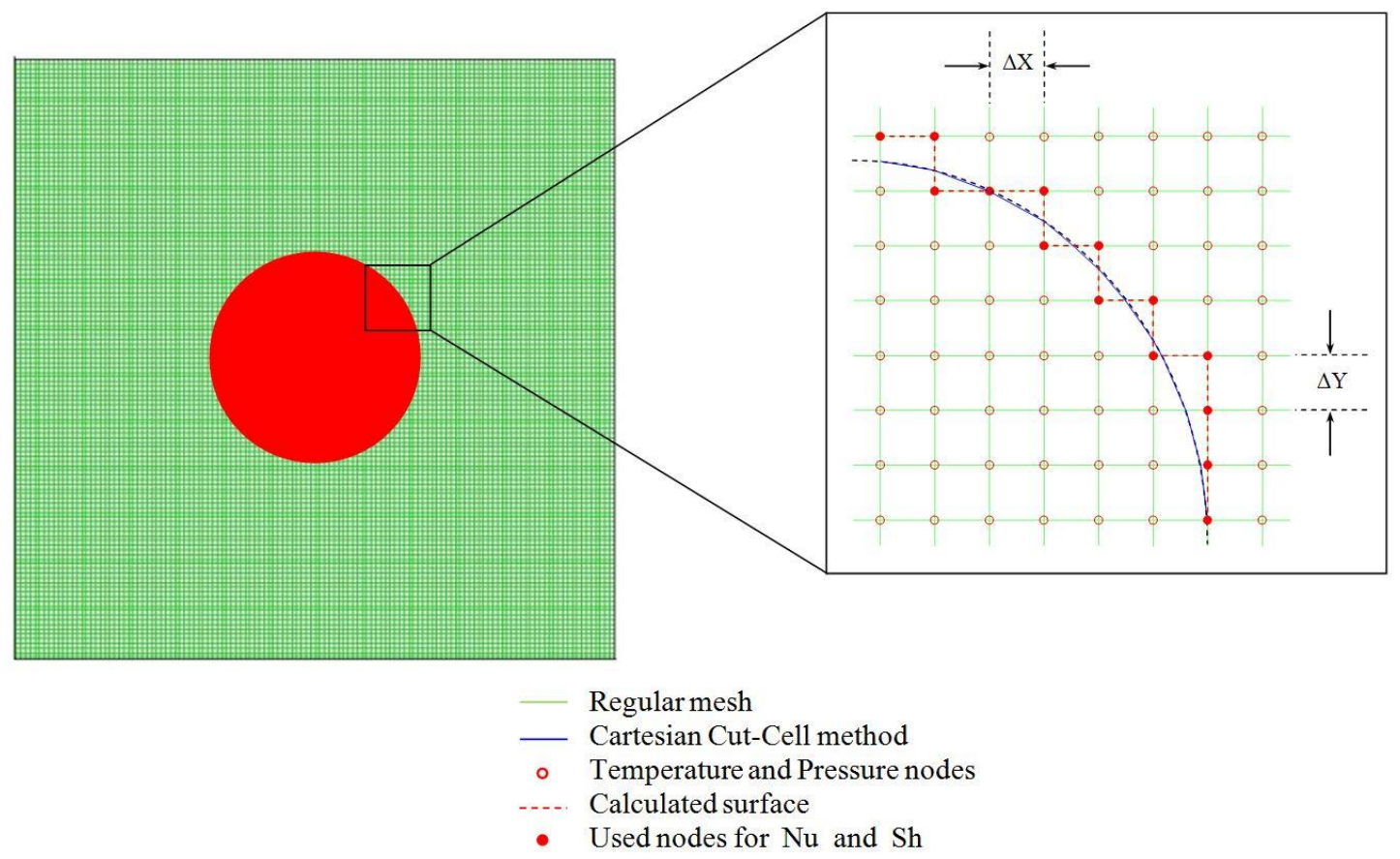

Figure 2. Grid arrangement and Cartesian Cut-Cell Method [31]

Noted that the convergence criterion for the computed temperature, concentration, pressure and velocity as well, can be defined as follows:

$$
\frac{\sum_{j=1}^{L} \sum_{i=1}^{M}\left|\xi_{i, j}^{k^{*}+1}-\xi_{i, j}^{k^{*}}\right|}{\sum_{j=1}^{L} \sum_{i=1}^{M}\left|\xi_{i, j}^{k^{*}+1}\right|} \leq 10^{-6}
$$

where both $\mathrm{M}$ and $\mathrm{L}$ are the grid points' numbers in $\mathrm{X}$ and $\mathrm{Y}$ directions, respectively. $\xi$ is any of the computed field variables, $\mathrm{k}^{*}$ is the iteration number, when $\mathrm{i}$ and $\mathrm{j}$ are the nodes according to the $\mathrm{X}$ and the $\mathrm{Y}$ directions.

To deal with the small cells which can be found arbitrarily cut reason to the Cartesian Cut-Cell adoption; Colella et al. [31] proposed to compute the fluid flow in the first part without taking these interfaces into account. Then, the loss interfaces can be calculated and distributed to the neighboring cells; based on the fluid mass which presents in each.

Once the velocity field together with the temperature and the solutal ones are obtained, the transfer rates of the pollutant surface can be computed using the following expressions:

Heat transfer rate: $\mathrm{Nu}=\left.\frac{\partial \theta}{\partial \mathrm{n}}\right|_{\text {source }} ; \mathrm{Nu}_{\mathrm{Avg}}=\frac{1}{\mathrm{~A}} \int_{0}^{\mathrm{A}} \mathrm{Nu} \mathrm{dS}$

Mass transfer rate: $\mathrm{Sh}=\left.\frac{\partial \phi}{\partial \mathrm{n}}\right|_{\text {source }} ; \mathrm{Sh}_{\mathrm{Avg}}=\frac{1}{\mathrm{~A}} \int_{0}^{\mathrm{A}} \mathrm{Sh} \mathrm{dS}$ where $\mathbf{n}$ is the normal direction respect to the pollutant surface (see for instance Fig. 2), and $\mathbf{A}$ is its surface area.

In the same way, heat and mass coefficients across the side walls of the porous square can be quantified using a wall surface' averaged Nusselt and Sherwood numbers, which based on the enclosure length scale " $\mathrm{H}$ ". Then, we write:

Heat transfer rate: $\mathrm{Nu}=\left.\frac{\partial \theta}{\partial \mathrm{X}}\right|_{\text {wall }} ; \mathrm{Nu}_{\mathrm{Avg}}=\int_{0}^{1} \mathrm{Nu} \mathrm{dY}$

Mass transfer rate: $\mathrm{Sh}=\left.\frac{\partial \phi}{\partial \mathrm{X}}\right|_{\text {wall }} ; \mathrm{Sh}_{\mathrm{Avg}}=\int_{0}^{1} \mathrm{Sh} \mathrm{dY}$

\section{RESULTS \& DISCUSSION}

\subsection{Code validation}

The performance of the using code against the doublediffusive phenomenon within a confined porous medium is established by comparing our predictions with other numerical results and experimental data; and by verifying the grid independence as well.

First of all, the present results are consistent with previous computations, namely those of Hadidi et al. [23]. By taking into account the same hypotheses, Table 1 demonstrates a comparison of the mean Nusselt and Sherwood numbers that computed with various values of the buoyancy ratio. As we can see, the present results and those of Hadidi et al. are in excellent agreement with a maximum discrepancy of about $1 \%$. 
Regarding the viscoplastic materials, the numerical code validity was already established in our previous works [33]. As shown Fig. 3, the computed transfer rate of various Bingham values with respect range of Rayleigh number within a square enclosure is found to be in excellent agreement with the ones plotted in the literature [21], as the maximum discrepancy is less than $1 \%$.

To ascertain the numerical code validity with the experimental thermosolutal data, those obtained by Weaver and Viskanta [34] for the mass transfer of an Ethanol/Nitrogen binary fluid as well as Ethanol/Helium one has been selected. Fig. 4(a,b) displays the comparison that made between the experimental data and both; the numerical Weaver and Viskanta predictions and the present ones, in term of velocity contours. Once again, our numerical results show a good qualitative concordance with the experimental data and a great agreement with the numerical Weaver \& Viskanta predictions.

Table 1. Transfer rates coefficients obtained with our computer code and those of Hadidi et al. [23]. $\mathrm{Bn}=0, \operatorname{Ra}=10^{6}, \mathrm{Pr}=7$, $\mathrm{Da}=10^{-4}$, Le $=10$

\begin{tabular}{ccc|cc|cc}
\hline \multirow{2}{*}{$\mathrm{N}$} & \multicolumn{2}{c|}{ Hadidi et al.[23] } & \multicolumn{2}{c|}{ Present predictions } & \multicolumn{2}{c}{$\Delta(\%)$} \\
\cline { 2 - 7 } & $\mathrm{Nu}_{\text {Avg }}$ & $\mathrm{Sh}_{\text {Avg }}$ & $\mathrm{Nu}_{\text {Avg }}$ & $\mathrm{Sh}_{\text {Avg }}$ & $\mathrm{Nu}$ & $\mathrm{Sh}$ \\
\hline 0 & 2.83 & 10.25 & 2.79 & 10.29 & $\mathbf{1 . 4 1}$ & $\mathbf{0 . 3 9}$ \\
\hline 10 & 3.95 & 26.30 & 3.91 & 26.33 & $\mathbf{1 . 0 1}$ & $\mathbf{0 . 1 1}$ \\
\hline 15 & 4.57 & 29.75 & 4.56 & 29.81 & $\mathbf{0 . 2 2}$ & $\mathbf{0 . 2 0}$ \\
\hline
\end{tabular}

$\Delta(\%)$ : Computed discrepancy value between the present results and those of Hadidi et al.[23]

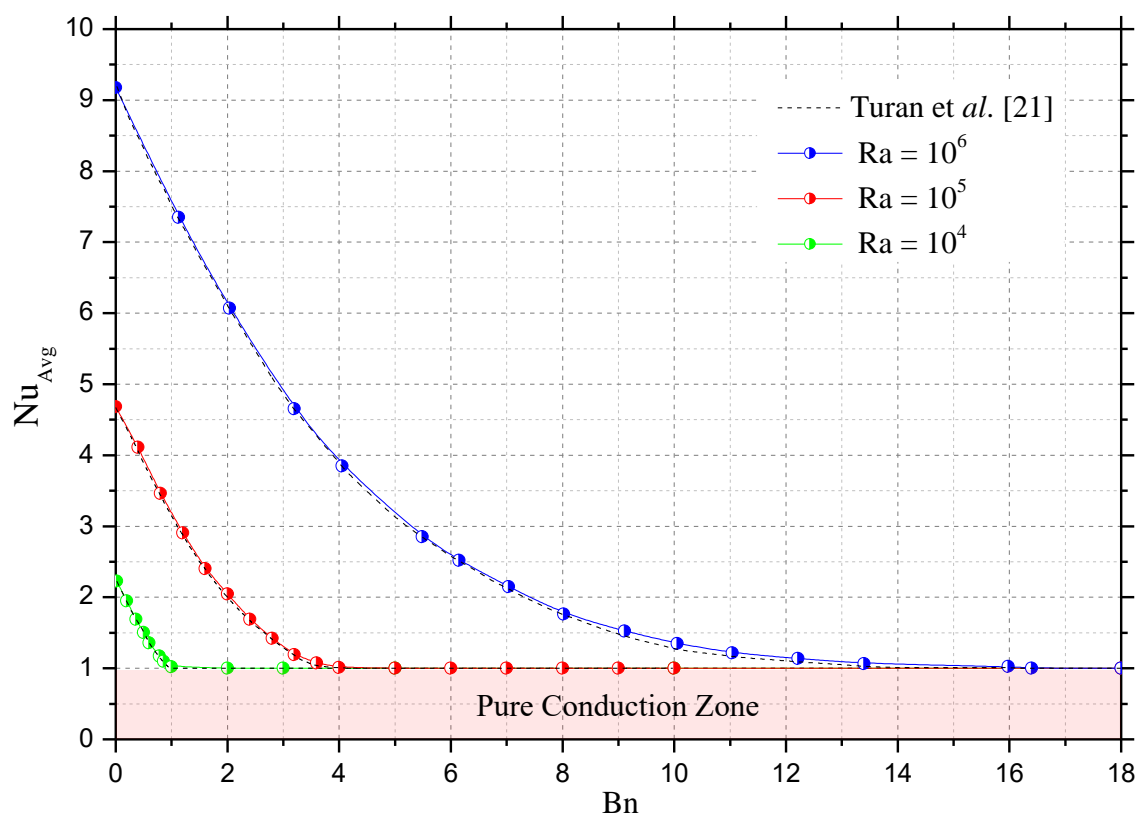

Figure 3. Mean Nusselt number of a Bingham fluid as a function of Rayleigh number. Validation with Turan et al. [21], Pr $=7$

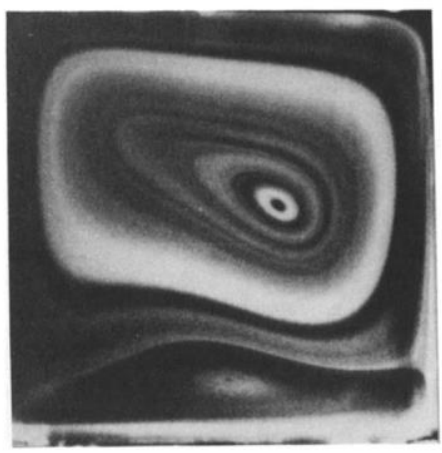

Weaver \& Viskanta [34]

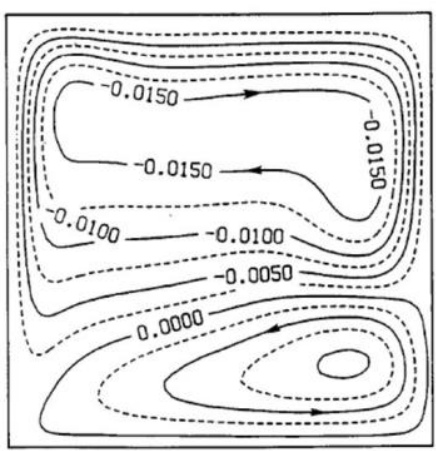

(a)

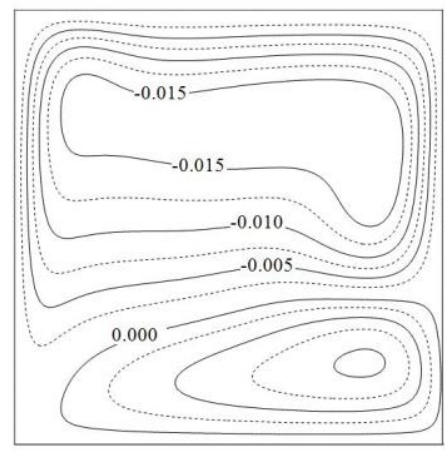

(b)

Present predictions

Figure 4(a). Ethanol / Nitrogen within a square enclosure.

(a) $\mathrm{Gr}=1.15710^{6} ; \mathrm{N}=-2.335 ; \mathrm{Pr}=0.802 ; \mathrm{Sc}=0.555$.

(b) $\mathrm{Gr}=1.12110^{6} ; \mathrm{N}=-2.328 ; \mathrm{Pr}=0.802 ; \mathrm{Sc}=0.557$ 

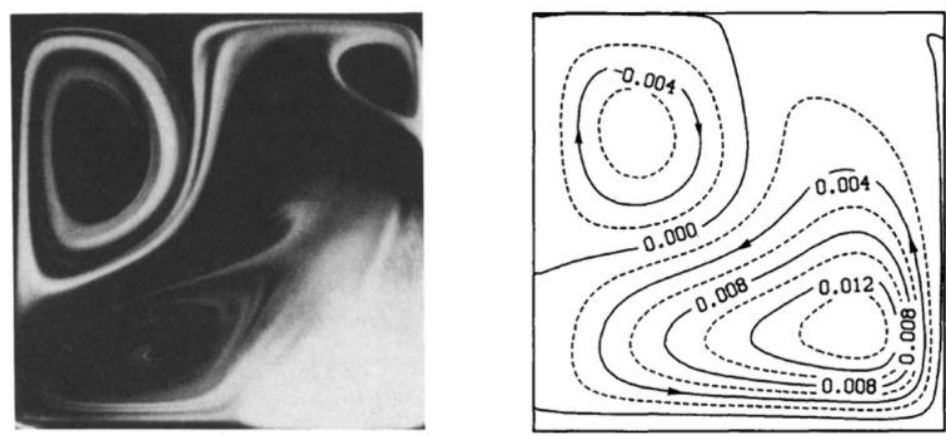

(a)

Weaver \& Viskanta [34]

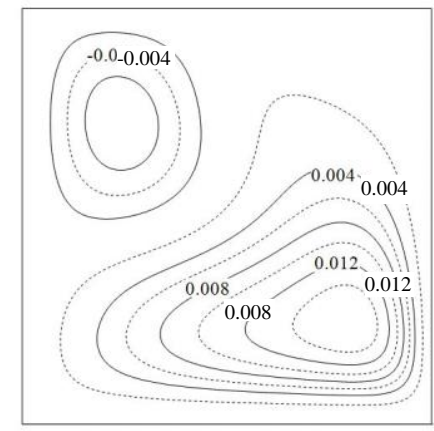

(b)

Present predictions

Figure 4(b). Ethanol / Helium within a square enclosure.

(a) $\mathrm{Gr}=2.71010^{4} ; \mathrm{N}=-5.475 ; \mathrm{Pr}=0.531 ; \mathrm{Sc}=1.574$.

(b) $\mathrm{Gr}=2.68910^{4} ; \mathrm{N}=-5.411 ; \mathrm{Pr}=0.533 ; \mathrm{Sc}=1.588$

Finally, and to check the numerical code validity with an inner circular pollutant, the obtained Kim et al. [35] predictions for a cold enclosure that contains a centred hot cylinder have been selected. Then, streamlines and Isotherm plots of Kim et al. side by side with the present ones are displayed through Fig. 5. As well, Table 2 summarizes the mean transfer rate of the pollutant source, which obtained for various Rayleigh values.
As far as the mean transfer rate is computed along the hot surface of the inner source (adopting Eq. 6.1); a great agreement between our results and both references [35-36] is denoted, as the maximum discrepancy still less than $1 \%$. Consequently, our numerical code can be used with great confidence against the circular pollutant source and the porous space as well.
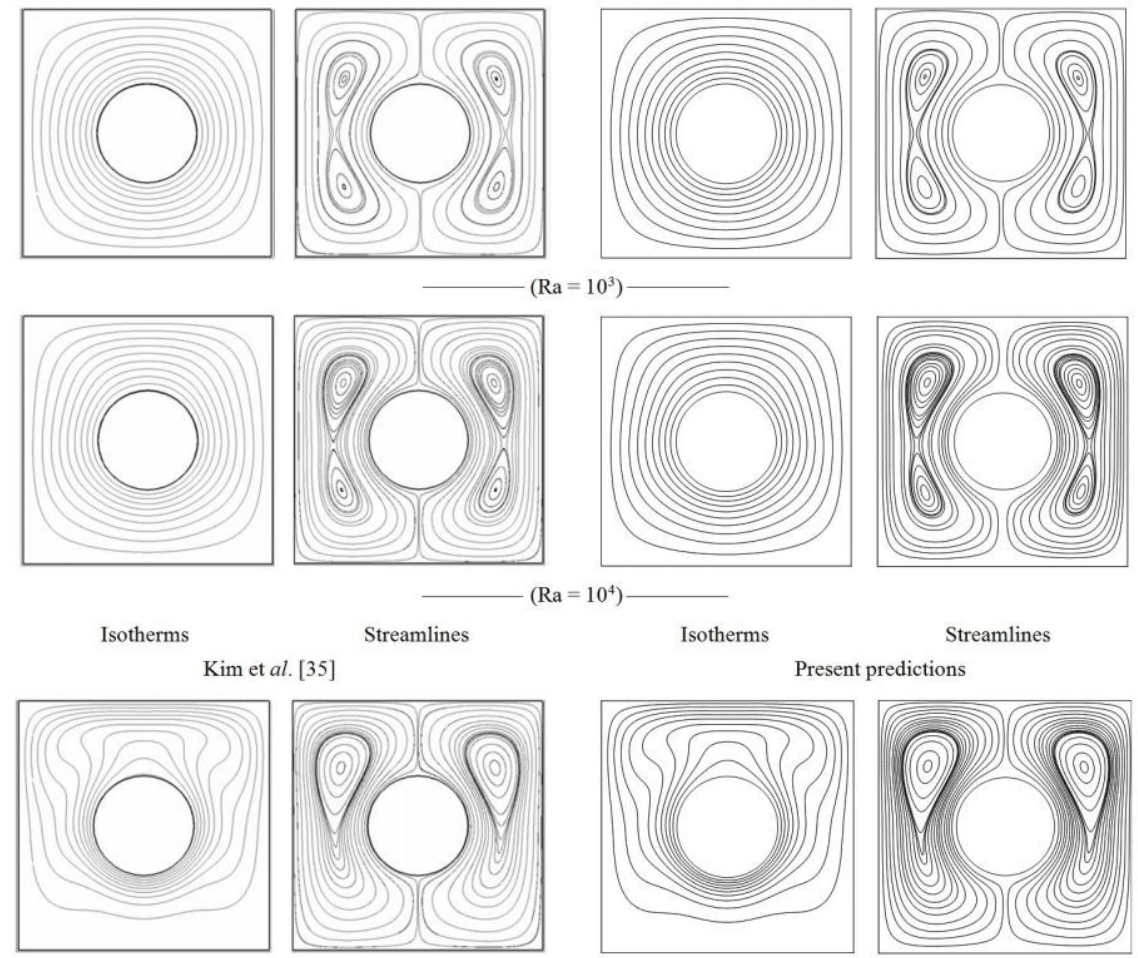

Streamlines

$\left(\mathrm{Ra}=10^{-}\right)$
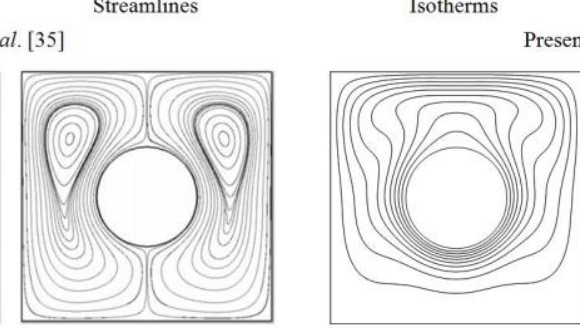

Streamlines
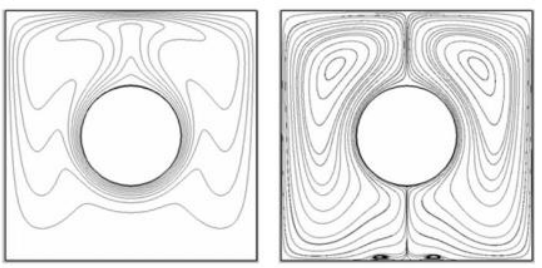

$\mathrm{Ra}=10^{5}$ )

Isotherms

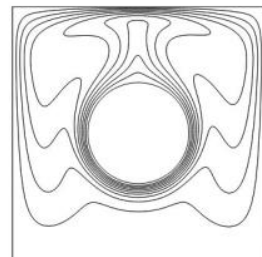

Isotherms

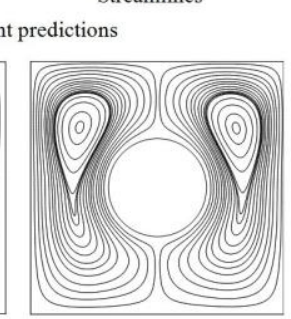

$$
\text { Streamlines }
$$

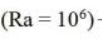

Kim et al. [35]

Present predictions

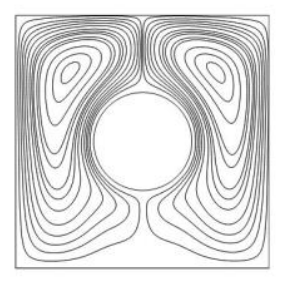

Streamlines

Figure 5. Fluid' streamlines and Isotherm plots respect to Rayleigh values. Comparison with Kim et al. results, $\operatorname{Pr}=0.71$ 
Table 2. Mean Nusselt number computed by the present code and those of references [35-36] for various Rayleigh values, $\operatorname{Pr}=0.71$

\begin{tabular}{c|c|c|c|c}
\hline Ra & Kim et al. [35] & $\begin{array}{c}\text { Sheikholeslami } \\
\text { et al. [36] }\end{array}$ & $\begin{array}{c}\text { Present } \\
\text { predictions }\end{array}$ & $\Delta(\%)$ \\
\hline $10^{3}$ & 4.95 & 4.97 & 4.97 & $\mathbf{0 . 4 2}$ \\
\hline $10^{4}$ & 5.03 & 5.09 & 5.05 & $\mathbf{0 . 4 0}$ \\
\hline $10^{5}$ & 7.71 & 7.67 & 7.72 & $\mathbf{0 . 1 3}$ \\
\hline
\end{tabular}

$\Delta \mathbf{( \% ) : ~ M a x i m u m ~ c o m p u t e d ~ d i s c r e p a n c y ' ~ v a l u e ~ b e t w e e n ~ t h e ~ p r e s e n t ~ r e s u l t s ~ a n d ~ r e f e r e n c e s ~ [ 3 5 , ~ 3 6 ] ~}$

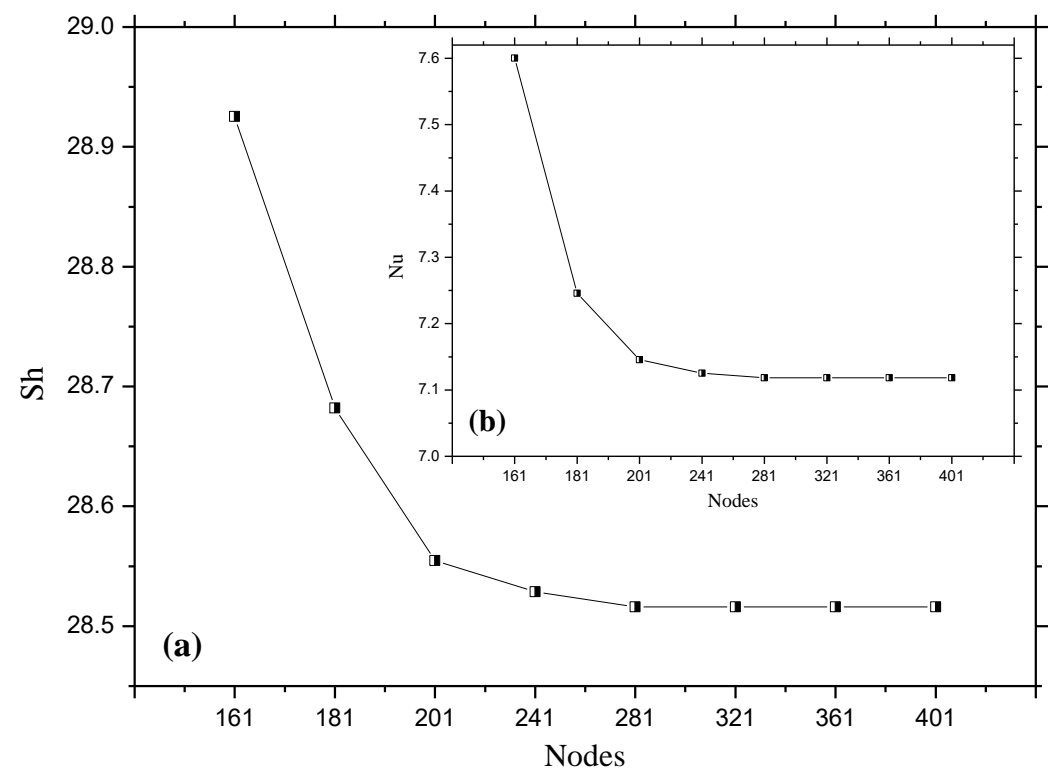

Figure 6. Mean Sherwood (a) and Nusselt numbers (b) with various uniform grids. $\mathrm{Bn}=5, \mathrm{Da}=10^{-3}, \mathrm{Le}=10, \mathrm{~N}=10, \mathrm{Ra}^{*}=100, \mathrm{~d} / \mathrm{H}=0.40$.

In order to determine a proper grid for our numerical simulations, a grid independence investigation is conducted for the conjugated phenomenon within the Bingham-porous square (previously shown in Fig.1). As such, several mesh distributions; ranging from $161^{2}$ to $401^{2}$; were tested all computing the mean transfer rates of the Bingham-square for the above uniform grids as displayed through Fig.6.

Subsequently, using a $201^{2}$ uniform grid is judged as adequate for a grid independent solution. However, a fine structured mesh of $241^{2}$ will be adopted to avoid round-off error for all other calculations in our investigation.

\subsection{Lewis \& buoyancy ratio' impacts}

The range of the pertinent parameters that has been examined through our study concerns the cooperating buoyancy forces' field. The value of the buoyancy ratio has been taken between 0 to 30 and that, for various porousthermal Rayleigh values $\left(\mathrm{Ra}^{*}=\mathrm{Ra}_{\mathrm{T}} \mathrm{Da}\right)$ which range from 100 to 2000 . The Lewis value has been taken between 10 and 300. As well; the source' diameter has been taken between $10 \%$ and $90 \%$ the enclosure' length; when Bingham, Prandtl and Darcy numbers are fixed at 5,10 and $10^{-3}$, respectively.

As the buoyancy ratio and the pollutant source diameter are fixed at 10 and $20 \%$, respectively, predictions illustrated in Fig. 7 have been obtained for two different values of Lewis number such as 10 and 100 , respectively.

By using the vertical velocity profile $\mathrm{V} / \mathrm{V}_{\max }$ in the midplane of the enclosure side by side with the temperature and the concentration ones, the complex fluid flow is found to be driven by a pure solutal buoyancy near the side-walls of the porous enclosure, as the temperature variation is proved to be insignificant. Near the pollutant source, all the opposite is denoted as the Bingham velocity is developed by a cooperating thermal and solutal buoyancies (simply said, thermosolutal buoyancy); caused by the combined impact of the temperature and the concentration variations.

As far as the Lewis value increases (as presented by the case of $\mathrm{Le}=100$ ); the mass boundary layer near the active walls gets slight which reflecting a great concentration gradient through such area. Contrasting, the thermal boundary layer gets thick; as the transition from a convection regime to a conduction one is developed through the porous enclosure.

Going far with our predictions, and when the Lewis value is about 10, Fig. 8 displays the impact of the buoyancy ratio on the Bingham-flow field, side by side with the temperature and the concentration. As previously found in Fig. 7, and near the side walls of the porous space, the Bingham' flow is driven by a pure solutal buoyancy as the temperature variation still irrelevant. Near the pollutant source, the buoyancy still caused by the cooperative effect of the temperature and the concentration variations.

Nevertheless; and unlike the Lewis impact, the increase in the buoyancy ratio makes the thermal and solutal boundary layers very thin near the active walls; what reflects the great thermosolutal gradient in the vicinity of this area. Such behavior may improve the local transfer characteristics (i.e. local $\mathrm{Nu}$ and $\mathrm{Sh}$ ) into these regions and so, the overall thermosolutal transfer within the viscoplastic-porous 
enclosure.

Regarding the yielded and unyielded regions within such geometry, a special behavior is denoted through the increasing values of the relevant parameters (i.e. Le and $\mathrm{N}$ ). In fact, and by presenting the unyielded region by a gray color within the streamlines, the latter is found to be more important against its quantity; respect to high Lewis values (see for instance Le $=100$ ). Indeed, the primary conduction regime (which developed within the porous enclosure at high Lewis values) helps the expansion of such rigid structure into the porous space, as the solutal buoyancy cannot drive the complex gel structure all alone.

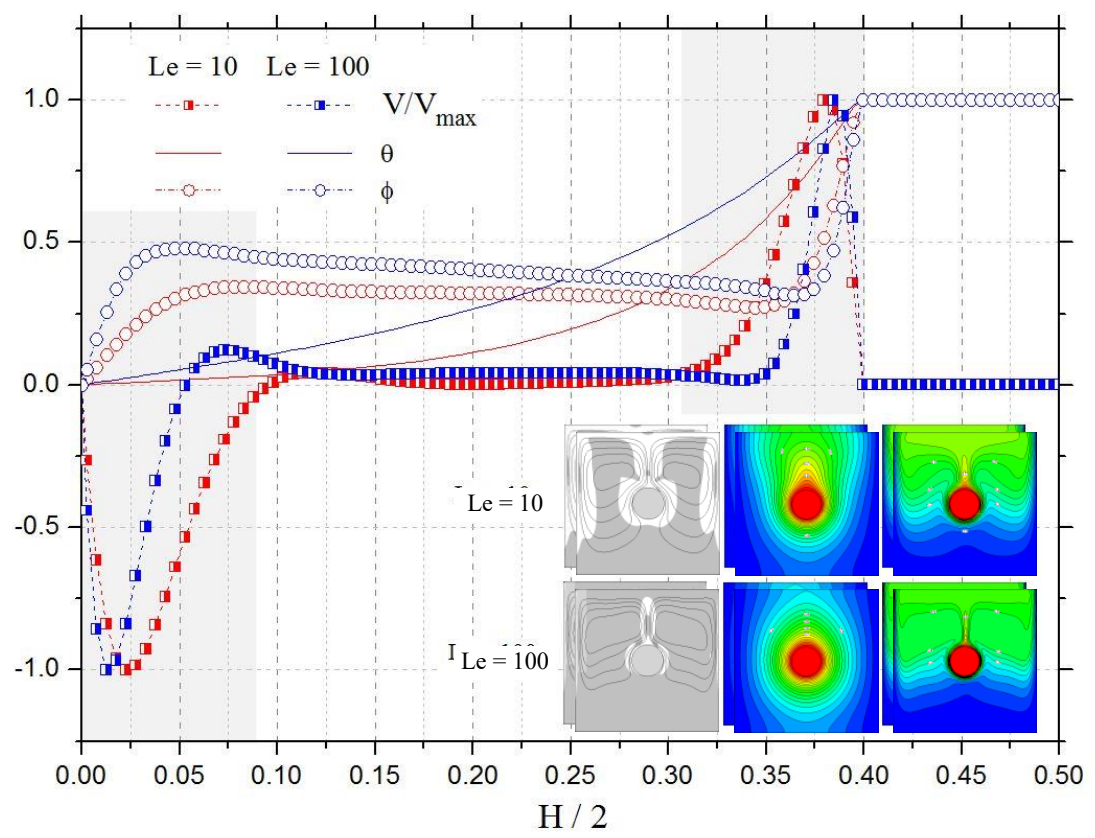

Figure 7. $V / \mathrm{V}_{\max }, \theta$ and $\phi$ profiles at the mid-section of the enclosure for various Lewis values. $\mathrm{Bn}=5, \mathrm{Da}=10^{-3}, \mathrm{~N}=10, \mathrm{Ra}^{*}=100, \mathrm{~d} / \mathrm{H}=20 \%$

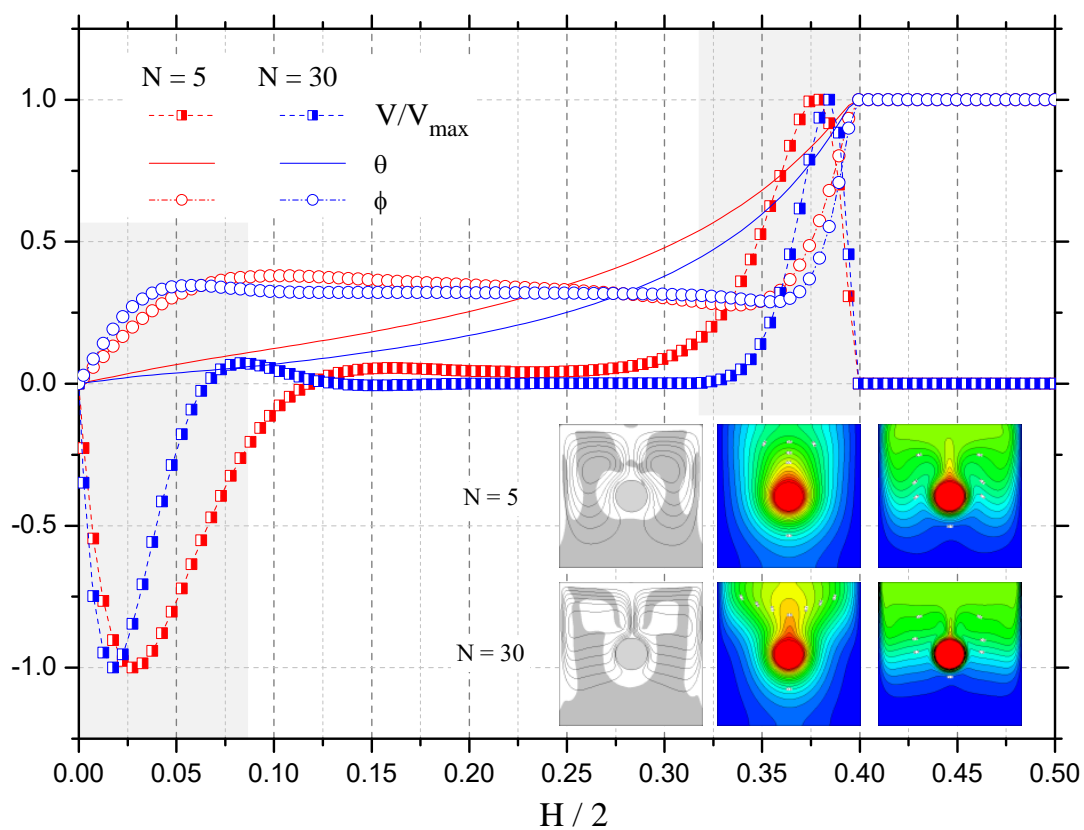

Figure 8. $V / \mathrm{V}_{\max }, \theta$ and $\phi$ profiles at the mid-section of the enclosure for various values of the buoyancy ratio. $\mathrm{Bn}=5$,

$$
\mathrm{Da}=10^{-3}, \mathrm{Le}=10, \mathrm{Ra}^{*}=100, \mathrm{~d} / \mathrm{H}=20 \%
$$

In a conflicting way, and by increasing the buoyancy ratio within the porous enclosure, such rigid structure of a Bingham fluid which appears within the enclosure for low buoyancy values (or high Lewis ones as pointed before) can be easily broken, as a cooperating impact of the thermal and the solutal buoyancies takes control within the porous space. Such behavior could be taken as a key factor to increase (or decrease) the fluid transfers within such geometries as will be following.

\subsection{Impact of the pollutant source' dimension}

As far as the impact of the pollutant source' dimension is conducted, Fig. 9 displays the transfer rates as a function of 
the source geometry (reported by the aspect ratio $(\mathrm{d} / \mathrm{H})$ ) and that, for various values of Lewis and buoyancy ratio. Through this part, the porous Rayleigh number $\mathrm{Ra}^{*}$ still fixed at 100 .

For a given value of Lewis (or $\mathrm{N}$ as well), a further increase in the source' dimension to $80 \%$ causes a significant improvement in thermosolutal convection within the porous enclosure, as the ratio $(\mathrm{d} / \mathrm{H})$ can control such phenomenon by increasing inner exchange surface into the porous square.

Going far with its value, the use of a pollutant source' dimension greater than $80 \%$ die out the impact of Lewis and buoyancy ratio on the mean heat transfer. Such phenomenon can be related to the developed conductive regime within the enclosure, which takes a full control on the square' heat transfer. The overall disappearance of the pertinent parameters (i.e. Le \& $\mathrm{N}$ ) is ascertained with a pollutant source' dimension of about $84 \%$.

However, following such critical value, (i.e. $d / H=80 \%$ ), the mass transfer rate decreases a little before starting another increase as long as the pollutant source' dimension increases. Such reduction in the diffusion transfer may be related to the fluid mass within the enclosure, which found very low and divided to four parts respect to the corners of the enclosure raison of the enhancement of the source dimension. The increase of the mass transfer rate, respect to the source dimension once again, can be related to the pure diffusion regime obtained in each corner of the porous enclosure.

Complement to what's presented previously, the impact of each pertinent parameter "i.e. the Lewis as well as the buoyancy ratio" on the transfer rates can be concluded through Fig.9. Simply said, and reason to the boundary layers' development within the porous space, both transfers are found as an increasing function of the buoyancy ratio. On the other hand, and unlike the mass transfer, the heat transfer can be only a decreasing function of increasing Lewis within the porous enclosure.
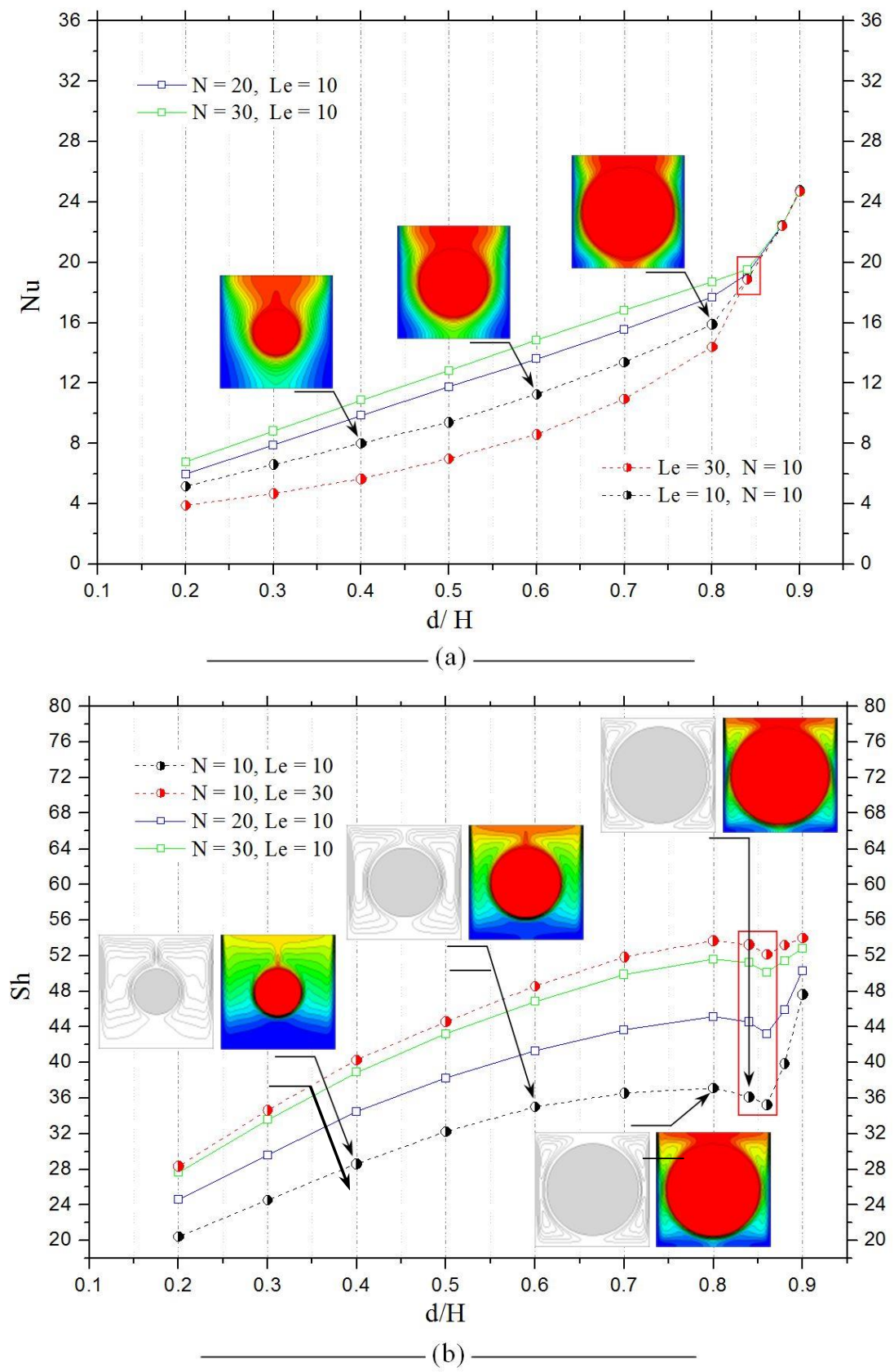

Figure 9. Mean Nusselt (a) and Sherwood numbers (b) as a function of the pollutant source' dimension. $\mathrm{Bn}=5, \mathrm{Da}=10^{-3}$, $\mathrm{Ra}^{*}=100$ 


\subsection{Proposed models}

Summarizing the numerical predictions; and by taking into account the previous observations; a powerful correlation that gives the mass transfer rate within such porous space is developed; based on the log-log presentation of Sherwood values with various aspect ratios $(\mathrm{d} / \mathrm{H})$ as displayed in Fig. 10(a). The latter, made using the solutal Rayleigh number $\left[\mathrm{Ra}^{*} \mathrm{Le}(\mathrm{N}+1)\right]$ and the aspect ratio $[\mathrm{d} / \mathrm{H}]$, is found available for a Lewis range of about 10 to 300, a buoyancy ratio in between 0 and 50, a porous-thermal Rayleigh number in between 100 and 2000, and a pollutant source' dimension less than $80 \%$.

$$
\begin{aligned}
& \left.\mathrm{Sh}\right|_{\mathrm{N} \geq 0}=0.7524\left[\frac{\mathrm{Ra}^{*} \mathrm{Le}(\mathrm{N}+1)}{(1-(\mathrm{d} / \mathrm{H}))^{3}}\right]^{0.3258} \\
& \left(\mathrm{R}^{2}=0.9960\right)
\end{aligned}
$$

The success in correlating the mass transfer rate led us to a search for a similar expression to predict our heat transfer. Adopting the statistical methods of previous works [37-39], this search was done successfully by using a Semilogarithmic presentation of Nusselt numbers with the dimensionless group $\left[\left(\mathrm{Ra}^{*} \mathrm{~N}(\mathrm{~d} / \mathrm{H})^{2.2}\right) / \mathrm{Le}\right]^{0.48}$ as shown Fig. 10(b) for instance. Then, a second correlation for the heat transfer rate within such porous space is found by giving $\mathrm{Nu}$ $=\mathrm{f}\left(1 / \mathrm{Le}, \mathrm{N}, \mathrm{Ra}^{*}\right.$ and $\left.\mathrm{d} / \mathrm{H}\right)$ as follows:

$$
\begin{aligned}
\left.\mathrm{Nu}\right|_{\mathrm{N}>0} & =2.338+1.7144\left[\left(\frac{\mathrm{Ra}^{*} \mathrm{~N}}{\mathrm{Le}}(\mathrm{d} / \mathrm{H})^{2.2}\right)^{0.48}\right] \\
& -0.034\left[\left(\frac{\mathrm{Ra}^{*} \mathrm{~N}}{\mathrm{Le}}(\mathrm{d} / \mathrm{H})^{2.2}\right)^{0.48}\right]_{\left(\mathrm{R}^{2}=0.9810\right)}^{2}
\end{aligned}
$$

This new expression still available within the previous ranges with an aspect ratio $\mathrm{d} / \mathrm{H}$ less than $78 \%$. Ending, it is worth to light out that such correlations (i.e. Eqs. 10-a \& 10-b) may count as a complement to previous researches which done in the case a Newtonian-annulus.

\section{CONCLUSION}

Through our paper, double-diffusive convection of a Bingham fluid within a Darcy-Brinkman porous space was numerically investigated. Using a centered thermosolutal source within the porous space; and by taking into account the impact of the pertinent parameters (as Lewis and buoyancy ratio), such double-diffusive contribution to the flow field is found very complicated; especially when coupling the impact of Lewis with the buoyancy ratio one. Then, follows-up the development of the boundary layers near the active walls was very required to make clear such complex contribution.
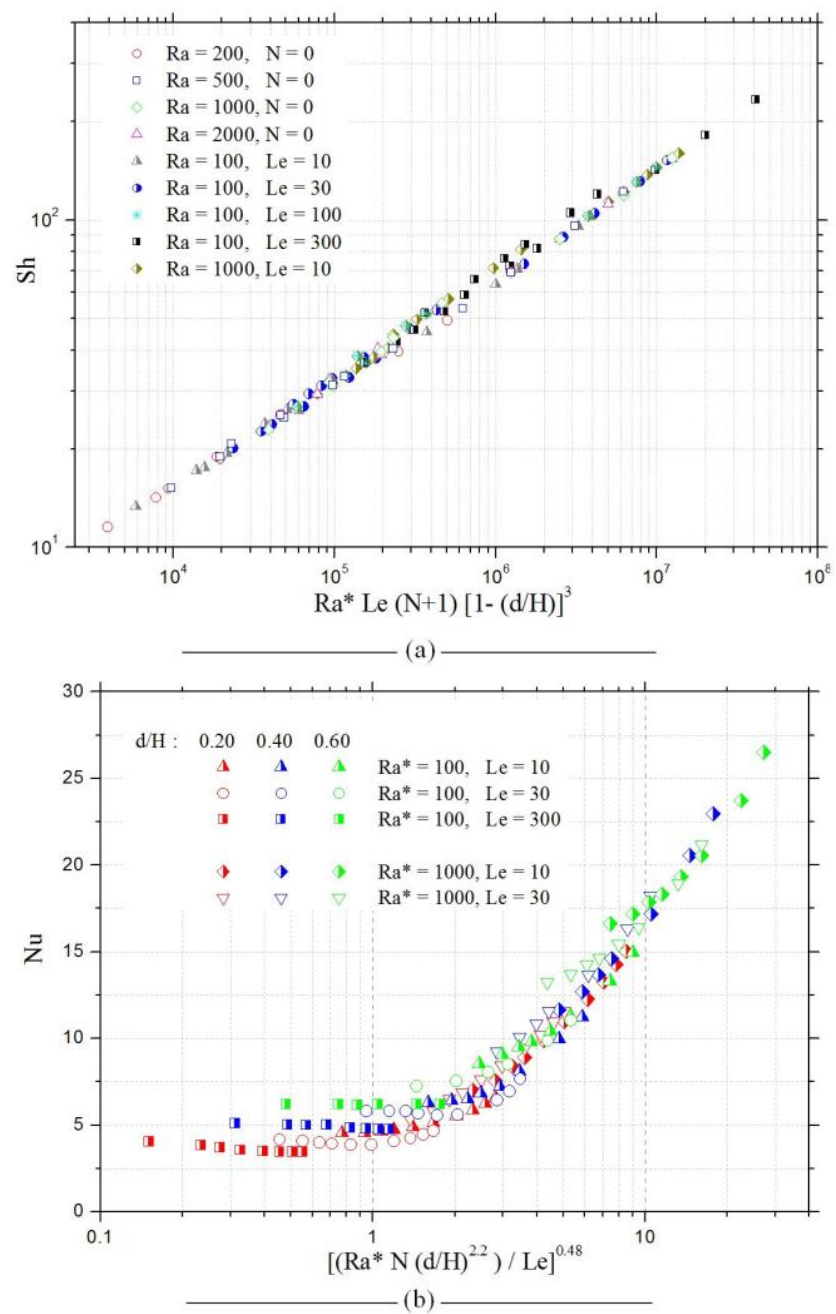

Figure 10. Modeling the transfer rates of the Bingham fluid within the porous square:

(a) Heat transfer rate, (b) Mass transfer rate. $\mathrm{Bn}=5$; $\mathrm{Pr}=10$ 
Additionally, and going far with its value, the use of a critical aspect ratio can die out the impact of any investigated parameter on such complex convection. Subsequently, only a heat conductive regime and a mass diffusive one can take control within the porous space.

Summarizing the numerical predictions; new correlations that compute the transfer rates within such complex geometry are successfully developed with a great precision. These original ones could be counted as a complement to previous researches done with the Newtonian-fluid case, and might prove particularly useful in verifying any instability analysis which might be put forth in the future.

Noted that the present investigation doesn't take into account the impact of other parameters; such as the porosity and the Darcy number, what provide guidance for future work.

\section{REFERENCES}

[1] Nield DA, Bejan A. (1992). Convection in porous media. Springer, Berlin. http://dx.doi.org/10.1007/9781-4757-2175-1.

[2] Mamou M, Vasseur P, Bilgen E. (1993). Multiple solution for double-diffusive convection in a vertical porous enclosure. Int. J. Heat Mass Transfer 36: 2479 2498. http://dx.doi.org/10.1016/0017-9310(94)00301-B

[3] Nithiarasu P, Seetharamo KN, Sundarajan T. (1996). Double-diffusive natural convection in an enclosure filled with fluid-saturated porous medium: A generalized Non-Darcy approach. Num. Heat Transfer Part A. 30: 413-426. http://dx.doi.org/10.1080/10407789608913848

[4] Ostrach S. (1980). Natural convection with combined driving forces. Phys-Chem. Hydrodynamic 1(04): $233-$ 247. http://dx.doi.org/1980PhChH.1.233O

[5] Kamotani Y, Wang LW, Ostrach S, Jiang HD. (1985). Experimental study of natural convection in shallow enclosures with horizontal temperature and concentration gradients. Int. J. Heat Mass Transfer 28: 165-173. http://dx.doi.org/1985IJHMT.28.165K

[6] Lee J, Hyun MT, Kim KW. (1988). Natural convection in confined fluids with combined horizontal temperature and concentration gradients. Int. J. Heat Mass Transfer 31(10): 1969-1977. https://doi.org/10.1016/00179310(88)90106-8

[7] Benard C, Gobin D, Thevenin J. (1989). Thermosolutale natural convection in a rectangular enclosure. Numerical Results. in Heat Transfer in Convective Flows, ASME, R. K. Shah, Ed., New York, 249-254. http://dx.doi.org/1985IJHMT.28.165K

[8] Han H, Kuehn TH. (1989). A numerical simulation of double diffusive natural convection in a vertical rectangular enclosure, in Heat Transfer in Convective Flows, ASME, R.K. Shah, Ed., New York, 149-154.

[9] Chang J, Lin TF. (1993). Unsteady thermosolutal opposing convection of liquid-water mixture in a square cavity- II: Flow structure and fluctuation analysis. Int. J. Heat Mass Transfer 36: 1333-1345. https://doi.org/10.1016/S0017-9310(05)80101-2

[10] Chen F. (1993). Double-diffusive fingering convection in a porous medium. Int. J. Heat Mass Transfer 36: 793807. https://doi.org/10.1016/0017-9310(93)80055-Y
[11] Trevisan O, Bejan A. (1987). Heat and mass transfer by high Rayleigh number convection in a porous medium heated from below. Int. J. Heat Mass Transfer 30(11): 2341-2356. https://doi.org/10.1016/00179310(87)90226-2

[12] Lin TF, Huang CC, Chang TS. (1990). Transient binary mixture natural convection in a square enclosure. Int. J. Heat Mass Transfer 33: 287-299. http://dx.doi.org/10.1016/0017-9310(90)90099-G

[13] Rachid B. (1993). Thermosolutal convection: fluid flow and heat transfer numerical simulations. Ph.D. Thesis, Pierre \& Marie Curie, Paris

[14] Ragui K, Boutra A, Benkahla YK. (2016). On the validity of a numerical model predicting heat and mass transfer in porous squares with a bottom thermal and solute source: Case of pollutants spreading and fuel leaks. Mech. \& Ind. 17: 311. http://dx.doi.org/10.1051/meca/2015109

[15] Bingham EC. (1916). An investigation of the laws of plastic flow. Bul Bur Standards 13: 309-353. https://archive.org/details/inv133093531916278278unse

[16] Bingham EC. (1922). Fluidity and plasticity. Mc Graw Hill, New-York, USA

[17] Mitsoulis E, Tsamopoulos J. (2017). Numerical simulations of complex yield-stress fluid flows. Rheol Acta. http://dx.doi.org/10.1007/s00397-016-0981-0

[18] Pascal H. (1983). Rheological behaviour effect of nonNewtonian fluids on steady and unsteady flow through porous media. Int. J. Num. Anal. Methods Geomech 07: 207-224. http://dx.doi.org/10.1002/nag.1610070303

[19] Amari B, Vasseur P, Bilgen E. (1994). Natural convection of non-Newtonian fluids in horizontal porous layer. Warme und Stoffubertragung 29: 185-199. https://doi.org/10.1007/BF01548603

[20] Ragui K, Boutra A, Bennacer R, Benkahla YK. (2016). Heat and mass transfer into a porous annulus found between two horizontal concentric circular cylinders. applied mechanics, behavior of materials, and engineering systems. Book Lect.Notes Mechanical Engineering, Springer. http://dx.doi.org/10.1007/978-3319-41468-3

[21] Turan O, Poole RJ, Chakraborty N. (2010). Aspect ratio effects in laminar natural convection of Bingham fluids in rectangular enclosures with differentially heated side walls. J. Non-Newtonian Fluid Mech. 166: 208-230. https://doi.org/10.1016/j.jnnfm.2010.12.002

[22] Turan O, Chakraborty N, Poole RJ. (2012). Laminar Rayleigh-Bénard convection of yield stress fluids in a square enclosure. J. Non Newtonian Fluid Mech. 171: 83-96. https://doi.org/10.1016/j.jnnfm.2012.01.006

[23] Hadidi N, Ould Amer Y, Bennacer R. (2013). Bilayered and inclined porous collector: Optimum heat and mass transfer. Energy 51: 422-430. https://doi.org/10.1016/j.energy.2013.01.012

[24] Papanastasiou TC. (1987). Flow of materials with yeld J. Rheol. 31: 385-404. https://doi.org/10.1122/1.549926

[25] Aniri A, Vafai K. (1994). Analysis of dispersion effects and non thermal equilibrium, non-Darcian, variable porosity incompressible flow through porous medium. Int. J. Heat Mass Tranfer 37: 939-954. http://dx.doi.org/0017-9310(93)E0019-D

[26] Noirot R. (1990). Experimental and parametric studies of soot combustion in a particulate filter: Application to 
Diesel exhaust gas purifying. $\mathrm{PhD}$ Thesis, Haute Alsace University, http://www.theses.fr/1990MULH0147

[27] Paiola J. (2017). Ecoulement d'un fluide à seuil dans un milieu poreux. Mécanique des fluides [physics.class-ph] Paris-Saclay University, France; NNT: 2017SACLS031. HAL Id: tel-01563941. https://tel.archivesouvertes.fr/tel-01563941

[28] Glowinski R, Wachs A. (2011). On the numerical simulation of viscoplastic fluid flow. In PG Ciarlet, JL Lions (eds.), Handbook of numerical analysis. Vol. 16, Num. Meth. Non Newtonian Fluids 06: 483-717. https://doi.org/10.1016/B978-0-444-53047-9.00006-X

[29] Nebbali R, Bouhadef K. (2006). Numerical study of forced convection in a 3D flow of a non-Newtonian fluid through a porous duct. Int. J. Numer. Methods Heat \& Fluid Flow 16(8): 870-889. http://dx.doi.org/10.1108/09615530610702041

[30] Ragui K, Boutra A, Bennacer R, Benkahla YK. (2018). Progress on numerical simulation of yield stress fluid flows (Part I): Correlating thermosolutal coefficients of Bingham plastics within a porous annulus of a circular shape. Int. J. Heat \& Mass Transfer 126: 72-94. https://doi.org/10.1016/j.ijheatmasstransfer.2018.05.010

[31] Colella P, Graves DT, Keen BJ, Modiano D. (2006). A cartesian grid embedded boundary method for hyperbolic conservation laws. J. Comput. Phys. 211(1): 347-366. http://dx.doi.org/10.1016/j.jcp.2005.05.026

[32] Patankar SV. (1980). Numerical heat transfer and fluid flow. Mc Grow, New York. ISBN 10: 0891165223 / ISBN 13: 9780891165224

[33] Ragui K, Benkahla YK, Labsi N, Boutra A. (2015). Natural convection heat transfer in a differentially heated enclosure with adiabatic partitions and filled with a Bingham fluid. J. Heat Transfer Research 08: 765-783. http://dx.doi.org/10.1615/2015007477

[34] Weaver JA, Viskanta R. (1992). Natural convection in binary gases driven by combined horizontal thermal and vertical solutal gradients. Exp. Thermal Fluid Sci. 05: 57-68. https://doi.org/10.1016/0894-1777(92)90056-B

[35] Kim BS, Lee DS, Ha MY, Yoon HS. (2008). A numerical study of natural convection in a square enclosure with a circular cylinder at different vertical locations Int. J. Heat Mass Transfer 51: 1888-1906. http://dx.doi.org/10.1016/j.ijheatmasstransfer.2007.06.0 33

[36] Sheikholeslami M, Gorji-Bandpy M, Pop I, Soheil S. (2013). Numerical study of natural convection between a circular enclosure and a sinusoidal cylinder using control volume based finite element method. Int. J. Thermal Science 72: 147-158 https://doi.org/10.1016/j.ijthermalsci.2013.05.004

[37] Cheng P. (1985). Natural Convection in Porous Media: External Flow. in Natural Convection. Fundamentals and Applications. Edited by S. Kakac, W. Aung and R. Viskanta, Martinus Nijhoff Publisher, The Haque, The Netherlands 475-513.

[38] Beghein C, Haghighat F, Allard F. (1992). Natural study of double-diffusive natural convection in a square cavity. Int. J. Heat Mass Transfer 35-4: 833-846. https://doi.org/10.1016/0017-9310(92)90251-M

[39] Goyeau B, Songbe JP, Gobin D. (1996). Numerical study of double-diffusive natural convection in a porous cavity using the Darcy-Brinkman formulation. Int. J.
Heat Mass Transfer 39-7: 1363-1378. https://doi.org/10.1016/0017-9310(95)00225-1

\section{NOMENCLATURE}

Bn Bingham number

C Dimensional mass fraction

$\mathrm{C}_{\mathrm{p}} \quad$ Specific heat at constant pressure, $\mathrm{J}_{\mathrm{kg}} \mathrm{kg}^{-1} \cdot \mathrm{K}^{-1}$

D Mass diffusivity, $\mathrm{m}^{2} \mathrm{~s}^{-1}$

d Pollutant source dimension, $\mathrm{m}$

Da Darcy number, $K / H^{2}$

g Gravitational acceleration, $\mathrm{m} . \mathrm{s}^{-2}$

$\mathrm{Gr}_{\mathrm{T}} \quad$ Thermal Grashof number, $g \beta_{T} \Delta T H^{3} / v^{2}$

$\mathrm{H} \quad$ Enclosure dimension, $\mathrm{m}$

$\mathrm{k}$ Thermal conductivity, W. $\mathrm{m}^{-1} \cdot \mathrm{K}^{-1}$

$\mathrm{K} \quad$ Porous medium permeability, $\mathrm{m}^{2}$

Le Lewis number, $\alpha / \mathscr{D}$

$\mathrm{N} \quad$ Buoyancy ratio, $\beta_{C} \Delta C / \beta_{T} \Delta T$

$\mathrm{Nu} \quad$ Nusselt number

$\mathrm{p} \quad$ Pressure, $\mathrm{Pa}$

P Dimensionless pressure, $p / \rho \beta_{T} \Delta T H$

Pr Prandtl number, $v / \alpha$

$\mathrm{Ra}_{\mathrm{T}} \quad$ Thermal Rayleigh number, $\rho g \beta_{T} \Delta T H^{3} / \mu_{p} \alpha$

Ra* Porous Rayleigh number, $R a_{T} D a$

Sh Sherwood number

$\mathrm{T}$ Dimensional temperature, $\mathrm{K}$

$\mathrm{u}, \mathrm{v} \quad$ Velocity components, $\mathrm{m} . \mathrm{s}^{-1}$

U, V Dimensionless velocity components,

$\mathrm{x}, \mathrm{y} \quad$ Cartesian coordinates, $\mathrm{m}$

$\mathrm{X}, \mathrm{Y}$ Dimensionless Cartesian coordinates, $=x$ (or $y) / H$

\section{Greek symbols}

$\alpha \quad$ Thermal diffusivity, $\mathrm{m}^{2}$. $\mathrm{s}^{-1}$

$\beta_{\mathrm{T}} \quad$ Thermal expansion coefficient, $\mathrm{K}^{-1}$

$\beta_{\mathrm{C}} \quad$ Solutal expansion coefficient

$\rho \quad$ Density, $\mathrm{kg} / \mathrm{m}^{3}$

$\phi \quad$ Dimensionless concentration

$\theta \quad$ Dimensionless temperature

$\tau \quad$ Shear stress, $\mathrm{N} / \mathrm{m}^{2}$

$\tau_{0} \quad$ Yield stress, $\mathrm{N} / \mathrm{m}^{2}$

$\bar{\tau} \quad$ Viscous stress' tensor

$\dot{\gamma} \quad$ Shear rate, $\mathrm{s}^{-1}$

$\mu_{\mathrm{p}} \quad$ Plastic viscosity, $\mathrm{N} \mathrm{s} / \mathrm{m}^{2}$

$\eta \quad$ Apparent viscosity, $\mathrm{N} \mathrm{s} / \mathrm{m}^{2}$

$\varepsilon \quad$ Porosity of the solid matrix

$\Psi \quad$ Stream function

$\delta_{\mathrm{C}} \quad$ Mass boundary layer thickness, $\mathrm{m}$

$\delta_{\mathrm{T}} \quad$ Thermal boundary layer thickness, $\mathrm{m}$

$\Delta(\%)$ results and literature references. 


\section{Subscripts}

0 Reference value

c Cold

h Hot
Avg Average

$+\quad$ Concentric

- $\quad$ Less concentric 